\title{
COMMENTS FROM THE PRESIDENT
}

\section{PRESIDENT'S MESSAGE}

$I^{\mathrm{n}}$ $n$ this president's message there are two topics for discussion: changes in the program of the annual meeting of The American Association for Thoracic Surgery and funding for graduate medical education.

In the late fall, the Association mailed a questionnaire to every member to help formulate a strategic plan. The idea for a strategic plan was first suggested by PastPresident Floyd Loop, and the Council, Officers, and administrative staff carried out the survey, the results of which were presented to the Council in December 1998. The results of this questionnaire indicated that the most important item to our membership is the annual meeting, our most visible educational activity. Members expressed a desire for more subspecialty sessions in General Thoracic, Adult Cardiac, and Pediatric Cardiac Surgery. Additionally, it was obvious to the Council that the last day of the program, as it is at most meetings, was underattended, which detracted from some terrific papers that are presented year after year. Therefore in December the Program Committee and the Council, in Boston, made changes in the program format that we believe will enhance your educational experience and provide a "value added" program, particularly on Wednesday morning. Second, we have decreased the number of plenary session papers by limiting the plenary sessions to Monday and Tuesday morning. We have increased the number of simultaneous session papers by presenting them on Monday and Tuesday afternoon. We have changed the Wednesday morning format completely. The Surgical Forum, both thoracic and cardiac, will be held as usual from 7:00 to 9:00 AM. Following this we have developed three lively debate topics in each of the three subspecialties, moderated by leading figures in these areas, entitled "Controversies in Cardiothoracic Surgery." We have chosen very controversial problems that should lead to a very informative program.

Tuesday morning will feature the Lillehei Cardiothoracic Resident Competition, supported by a grant from St Jude Medical, Inc. A $\$ 5000$ prize will be presented for the best paper/presentation. The award will be based on a

J Thorac Cardiovase Surg 1999;117:636-7

Copyright $\odot 1999$ by Mosby, Inc.

$0022-5223 / 99 \$ 8.00+0 \quad 12 / 1 / 96992$ manuscript completed in advance, presentation, and response to critique. Eight excellent papers have been chosen, indicating the high level of performance that our cardiothoracic surgical residents have put forth for this meeting. Both the Basic Science Lecturer and the Honored Guest Speaker

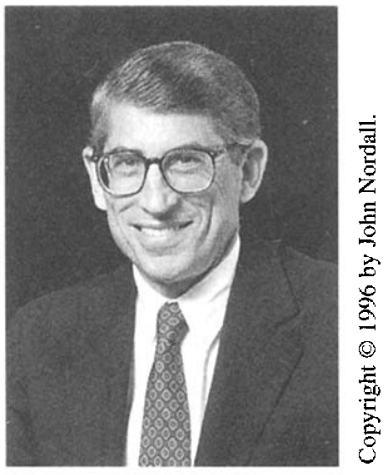
will also present their lectures on Tuesday morning. As I mentioned in a previous presidential page, the three postgraduate courses on Sunday are extremely provocative. For the first time, we will have a symposium entitled "Developing the Academic Surgeon," a half day designed to help the academic cardiothoracic surgeon. The preliminary program of the annual meeting is printed in this issue of the Journal, and you will see some of the changes. In our opinion this restructuring is a "work in progress," and we will be interested in comments and suggestions related to this change in our annual meeting.

I would like to make some additional reflections on postgraduate medical education, another timely topic. After a presidential page ${ }^{1}$ discussing this in the context of the educational mission of the AATS, I received on December 22, 1998, a memo from the American Association of Medical Colleges outlining probable reductions and/or changes in graduate medical education funding by the federal government by direct Medicare payments. Many of us who are interested in the education of cardiothoracic surgeons have been predicting these events for some time and have been calling for revisions in our thoracic surgical residency training programs so that we might be prepared for the changes in funding, the length of time of thoracic surgical training, as well as the numbers of residents trained. The government looks at graduate medical education as another major effort to reduce the funding of the Medicare program. This topic of major change in traditional thoracic resident training was first brought to our attention by President Mortimer J. Buckley in his presidential address. ${ }^{2}$ In my recent message, I indicated that the Joint Council on Thoracic Surgical Education, 
chaired by Andrew Wechsler, MD, is preparing to look at the entire field of thoracic surgical training. It is my prediction that in the next year or two, with all of the important players representing the American Board of Thoracic Surgery, the Residency Review Committee, the Thoracic Surgical Directors' Association, the Society of Thoracic Surgeons, the American College of Surgeons, and our Association, we will create a modification of the traditional training of a cardiothoracic surgical resident. It is very important that we be proactive on this matter and have our collective strategy outlined. When and if these changes arise, we should be prepared with a cohesive, comprehensive, and realistic program for the future of thoracic surgical resident edu- cation. There will be much debate and discussion about the next steps to take in this area, but working together with the aforenamed organizations and societies we should be able to accomplish what needs to be done practically and economically and still preserve our tradition of excellence in thoracic surgical education.

Lawrence H. Cohn, MD

Boston, Massachusetts

\section{REFERENCES}

1. Cohn LH. Message from the president of The American Association for Thoracic Surgery. J Thorac Cardiovasc Surg 1999;177:201-2.

2. Buckley MJ. I would like to be a thoracic surgeon. J Thorac Cardiovasc Surg 1996:112:1135-42. 